\title{
28 Research Square \\ Simultaneous Beat-To-Beat Heart Rate And Systolic Blood Pressure Variability In Patients With And Without Neurally Mediated Syncope
}

Amirhossein Akbarzadeh

Tabriz University of Medical Sciences

Fariborz Akbarzadeh

Tabriz University of Medical Sciences

Babak Kazemi ( $\sim$ bkazemia1966@gmail.com )

Tabriz University of Medical Sciences

\section{Research Article}

Keywords: Syncope, Blood pressure variability, tilt test, Heart rate variability, Finapress

Posted Date: June 8th, 2021

DOI: https://doi.org/10.21203/rs.3.rs-569717/v1

License: (c) This work is licensed under a Creative Commons Attribution 4.0 International License. Read Full License 


\section{Abstract}

Background: Autonomic changes play an essential role in the genesis of neurally mediated syncope (NMS). The aim of this study was to compare the changes of the autonomic nervous system (ANS) by measuring spectral indices of beatto-beat systolic blood pressure and heart rate variability (SBPV and HRV) in ranges of low frequency (LF), high frequency (HF), and the LF/HF ratio during head-up tilt test (HUTT) in patients with and without a syncope response.

Methods: In this case-control study of 46 patients with a suspected history of unexplained syncope, data were recorded separately during the typical three phases of HUTT. Patients who developed syncope were designated as the case group and the rest as the control group.

Results: Thirty one patients experienced syncope during HUTT. Resting HRV and SBPV indices were significantly lower in cases than controls. After tilting in the syncope group, both HF and LF powers of SBPV showed a significant and gradual decrease. LF/HF in HRV increased in both groups similarly during the test but in SBPV, mainly driven by oscilations in its LF power, it increased significantly more during the first two phases of the test in syncope patients only to paradoxically decrease during active tilt $(p<0.001)$.

Conclusion: Our findings show an abnormal autonomic function in patients with syncope, both at rest and tilting. Fluctuations of spectral indices of beat-to-beat SBPV, a potential noval index of pure sympathetic activity, show an exaggerated response during tilt and its withdrawal before syncope.

\section{Key Points Summary}

- There have been few studies that evaluated simultaneous beat-to-beat heart rate variability and systolic blood pressure variability in patients with and without syncope during the head-up tilt test.

- Traditionally, power spectural analysis of heart rate variability has been a widespread guide for the assessment of autonomic nervous system characteristics such as parasympathetic/sympathetic function or sympathovagal balace

- The main result of this study, aside from showing the feasibility of these mesurements dring head-up tilt test, was the clarification of low frequency fluctuations of systolic blood pressure variability, a potential noval index of pure sympathetic activity, during syncope.

- These flactuations show sympathetic withdrawal as the main mechanism of neurally mediated syncope.

\section{Introduction}

Syncope is defined as a rapid and transient loss of consciousness due to a brief decline in cerebral blood flow with spontaneous and complete recovery after falling. One to two percent of emergency visits are due to syncope, and about half of these patients are admitted to the hospital ${ }^{1}$. Neurally mediated syncope (NMS) accounts for $55-60 \%$ of all unexplained syncope cases ${ }^{2}$. It has been believed that the main cause of NMS is the stimulation of the parasympathetic system due to the Bezold Jarish reflex in the empty left ventricle. Subsequently, severe decrement in blood pressure (BP) and or heart rate (HR) causes loss of consciousness and fainting. Although this mechanism is generally accepted, this theory was questioned by findings after cardiac transplantation ${ }^{3}$. On the other hand, the neurohormonal mechanism may start the cascade of events that eventually cause syncope ${ }^{4}$.

BP and HR constantly oscillate over time under the influence of control mechanisms such as autonomic nervous system (ANS), humoral factors, and respiration for maintaining cardiovascular homeostasis. Among the methods used for analyzing these oscillations, power spectural analysis of heart rate variability (HRV) has become an increasingly 
widespread guide for the assessment of ANS characteristics such as parasympathetic/sympathetic function or sympathovagal balace ${ }^{5,6}$. The breath-dependent high frequency (HF) oscillations of HR give information about the parasympathetic (cardiovagal) activity and are usually about $0.2-0.3 \mathrm{~Hz}$ according to the usual breathing frequency (one breath every 3rd to 5th second). However, the low frequency (LF) oscillations of HR which has its summit at approximately $0.1 \mathrm{~Hz}$ are not a reliable index for the pure sympathetic activity, since different variables are involved in their origin. They become influenced by i.e. changes in the venous return, cardiac filling, the baroreceptor reflexes and the cardiac sympathetic activity 7,8 . In contrast, information regarding ANS provided by SBPV is different from that provided by HRV. SBPV can also be analyzed on the basis of LH and HF of the power spectrum but it has been believed that the LF power of SBPV may be mediated primarily by the sympathetic nervous system ${ }^{9}$.This sympathetic drive can be easily measured by the Task Force ${ }^{\circledR}$ Monitor software from the SBPV.

Conflicting data have been reported on autonomic control during the HUTT phases prior to syncope, some reporting decreased sympathetic activity ${ }^{10}$, some showing increased sympathetic activity ${ }^{11}$, one describing both patterns ${ }^{12}$ and two studies reporting increased parasympathetic activity ${ }^{13,14}$. A better understanding of the pathophysiology of tilt induced syncope could provide a more rational basis for the therapy of syncope.

Searching literature showed few published articles with simultaneous evaluation of beat-to-beat HRV and SBPV in patients with $\mathrm{NMS}^{3,15-18}$. To enrich the relevant data on mechanisms of NMS in adults, especially in the field of beat-tobeat SBPV, we decided to conduct this study. The primary goal of this study was to investigate the changes in HRV and SBPV during HUTT in patients with and without syncope. The results of this study can be used to help clarify the role of the ANS, specially the sympathetic nervous system by measuring the LF power of beat-to-beat SBPV, in the genesis of NMS. The availability of the Task Force ${ }^{\circledR}$ Monitor which performs simultaneous beat-to-beat HRV and SBPV analysis during phases of HUTT is an excellent opportunity in this regard.

\section{Materials And Methods}

In this case-control study between April 2018 and April 2019, patients with a suspected history of unexplained syncope during the previous six months, aged 18 to 40 years who accepted to participate in this study, were prospectively recruited. The LF and HF powers and their ratio of HRV and SBPV were recorded simultaneously during the typical three phases of HUTT (rest, passive tilt, and active tilt with nitroglycerine). Patients who developed syncope were designated as the case group and the rest as the control group. The Research Ethics Committee of Tabriz University of Medical Sciences approved this study (approval ID: IR.TBZMED.REC.1397.602). Subjects with diabetes, movement disorders such as Parkinson's disease and multiple systemic atrophy, congestive heart failure of any cause, ischaemic cardiomyopathy and previous myocardial infarction, severe valvular heart disease, severe pulmonary hypertension, carotid sinus hypersensitivity, uncontrolled systemic hypertension, and severe chonic kidney disease were excluded because the HRV pattern could have been affected by their underlying disease. Drugs which interact with autonomic modulation were discontinued for at least five half-lives before the day of testing. Patients with a history of psychiatric illness who were on psychiatric drugs or had permanent atrial fibrillation, grade two or three atrioventricular-nodal block, complete bundle branch block, pacemaker rhythm, frequent extra-stimulus in resting ECG, or signs of channelopathies in resting ECG, and those who were reluctant to complete the test were also excluded from the study. After taking a complete history and physical exam, data on baseline characteristics of patients including age, sex, height, weight, and full drug history were collected. ECG and echocardiographic study were done for all patients. Informed consent for doing the test and attending the research protocol was obtained from all patients. HUTT was performed according to the Italian protocol ${ }^{19}$ after at least four hour fasting in the afternoon in a quiet room with dimmed lights and adjusted temperature around $24^{\circ} \mathrm{C}$. A skilled nurse prepared the patients, and the tests were done under the direct supervision of a cardiologist. The test was performed by means of an electrically controlled tilt table with a footboard for weight bearing. After a 
resting period of 6 minutes in the supine position, the patient was tilted to $70^{\circ}$ for 25 minutes (passive phase). Thereafter, in the absence of spontaneous syncope, $400 \mu \mathrm{g}$ of nitroglycerine spray were administered subligually and the patient remained tilted for an additional 20 minutes (provocation phase), unless syncope occurred. The test was considered completed either with the occurrence of syncope or ending of the provocation phase in the absence of symptoms. The haemodynamic response to HUTT was classified according to the VASIS classification [cardioinhibitory $(\mathrm{CI})$, vasodepressor (VD), or mixed types] ${ }^{20}$.

Surface ECG and beat-to-beat SBPV and HRV were simultaneously recorded using the Task Force® Monitor System (CNSystems Medizintechnik GmbH, Austria). The Task Force ${ }^{\circledR}$ Monitor System is a device for continuous noninvasive assessment of hemodynamic and autonomic regulation of the cardiovascular system and is particularly useful in the diagnostic processing of patients with syncope. With the special software, ECG, HR, and BP are recorded and visualized during the HUTT and then all the data are exported for evaluation. BP was measured beat-to-beat on the finger artery with a suitable sized double finger sensor attached to the third and fourth fingers of the right hand, using CNAP technology. With the so-called vascular unloading technique, plethysmographic signals are transformed into continuous BP information. The so-called VERIFI-algorithm is applied to overcome the problem of bias caused by vasoconstriction or vasodilatation ${ }^{20}$. A separate left-arm pressure cuff was applied to take BP every 5 minutes. Recordings with artefacts in a signal involved in total more than $10 \%$ of values were excluded from further analysis; signals with less than $10 \%$ artefacts were edited (the erroneous values were replaced by the median of the surrounding seven correct values) ${ }^{21}$. Frequency power indices of both HRV and SBPV, including LF, HF, and LF/HF ratios, were recorded. The original recorded files were in the format of text files which were converted to data files for further analysis. In the first step of the analysis, the entire beat-to-beat data were analyzed and summarized for all study groups with and without syncope. In the second stage of the study, beat-to-beat data were divided into 30 seconds blocks and the mean of each block was used for drawing more informative figures. Finally, we compared the HRV and SBPV indices separately between case and control groups. All methods were carried out in accordance with relevant guidelines and regulations.

\section{Statistical Analysis:}

The Excel software for windows was used for data collection and entry. Continuous quantitative data were expressed as mean \pm SD and compared between groups by student $t$-test and the ANOVA test. A comparison of quantitative data in each group at different phases of HUTT was made by paired samples t-test. Qualitative data were presented as frequency, and no comparisons were made. A P-value of less than or equal to 0.05 was considered a statistically significant difference between variables. Figures were drawn by Powerpoint 2016 software for windows. We used two statistical softwares, SPSS 22 for windows and web-based open EPI Info in this study.

\section{Results}

\section{Baseline characteristics and general information:}

Fifty three of seventy two patients who were referred to our outpatient syncope clinic between April 2018 to April 2019 were eligible to participate in this study. Three patients withdrew their consent to take part in the study and the data on four patients were corrupted. Finally, 46 patients (31 patients in case and 15 patients in the control group) were analysed. Baseline characteristics of patients are summarised in Table 1. Because of the strict inclusion and exclusion criteria, all patients had a healthy heart. Therefore echocardiographic and electrocardiographic results of patients are not shown. 
Table 1

Baseline characteristics of patients

\begin{tabular}{|c|c|c|c|c|c|}
\hline Groups (no) & Male/female & $\begin{array}{l}\text { Mean } \\
\text { Age } \\
\text { Y (SD) }\end{array}$ & $\begin{array}{l}\text { Mean Height CM } \\
\text { (SD) }\end{array}$ & $\begin{array}{l}\text { Mean } \\
\text { Wight } \\
\text { KG (SD) }\end{array}$ & $\begin{array}{l}\text { Body surface area } \\
\mathrm{m}^{2} \text { (SD) }\end{array}$ \\
\hline No Syncope (15) & $13 / 2$ & $\begin{array}{l}27.13 \\
(6.46)\end{array}$ & $173.80(9.45)$ & $\begin{array}{l}68.73 \\
(15.02)\end{array}$ & $1.82(0.21)$ \\
\hline Syncope (31) & $16 / 15$ & $\begin{array}{l}29.16 \\
(8.97)\end{array}$ & $170.55(9.68)$ & $\begin{array}{l}75.23 \\
(13.48)\end{array}$ & $1.82(0.20)$ \\
\hline Cardioinhibitor Syncope (12) & $8 / 4$ & $\begin{array}{l}28.33 \\
(7.94)\end{array}$ & $172.42(10.05)$ & $\begin{array}{l}8.67 \\
(15.61)\end{array}$ & $1.93(0.21)$ \\
\hline Mixed Type Syncope (12) & $4 / 8$ & $\begin{array}{l}30.67 \\
(10.12)\end{array}$ & $168.00(9.04)$ & $\begin{array}{l}74.00 \\
(8.50)\end{array}$ & $1.80(0.17)$ \\
\hline Vasodepressor Syncope (7) & $4 / 3$ & $\begin{array}{l}28.00 \\
(9.59)\end{array}$ & $171.71(10.59)$ & $\begin{array}{l}68.00 \\
(12.39)\end{array}$ & $1.79(0.19)$ \\
\hline $\begin{array}{l}\text { Significance (Syncope/No } \\
\text { Syncope) }\end{array}$ & 0.02 & 0.43 & 0.28 & 0.14 & 0.66 \\
\hline
\end{tabular}

In the case group, 9 (29.1\%) developped syncope in the passive phase of the test ( $6 \mathrm{Cl}, 1 \mathrm{VD}$, and 2 mixed type). Twenty two patients (70.9\%) developped syncope in the active pase of the test (6 Cl, $6 \mathrm{VD}$, and 10 mixed type). 
Table 2

Comparison of mean (SD) HRV $\left(\mathrm{ms}^{2}\right)$ and SBPV $\left(\mathrm{mmHg}^{2}\right)$ indices in patients with and without syncope.

\begin{tabular}{|c|c|c|c|c|c|c|c|c|c|c|c|}
\hline \multicolumn{2}{|c|}{ Index/Group } & \multicolumn{5}{|l|}{ HRV } & \multicolumn{5}{|l|}{ SBRV } \\
\hline & & control & $\mathrm{Cl}$ & VD & Mixed & Case & control & $\mathrm{Cl}$ & VD & Mixed & Case \\
\hline & & 15 & 12 & 7 & 12 & & 15 & 12 & 7 & 12 & 31 \\
\hline \multirow[t]{4}{*}{ LF } & Rest & $\begin{array}{l}461 \\
(69)\end{array}$ & $\begin{array}{l}294 \\
(71)^{\star}\end{array}$ & $\begin{array}{l}277 \\
(50) \text { * }\end{array}$ & $\begin{array}{l}500 \\
(290)\end{array}$ & $\begin{array}{l}371 \\
(113)\end{array}$ & $\begin{array}{l}14.28 \\
(0.93)\end{array}$ & $\begin{array}{l}8.16 \\
(0.77) \star\end{array}$ & $\begin{array}{l}6.13 \\
(0.23) \star\end{array}$ & $\begin{array}{l}4.71 \\
(0.52) \star\end{array}$ & $\begin{array}{l}6.38 \\
(0.45) \\
9\end{array}$ \\
\hline & $\begin{array}{l}\text { Tilt } \\
70\end{array}$ & $\begin{array}{l}529 \\
(1936)\end{array}$ & $\begin{array}{l}593 \\
(9569)\end{array}$ & $\begin{array}{l}239 \\
(1166)\end{array}$ & $\begin{array}{l}246 \\
(583) *\end{array}$ & $\begin{array}{l}363 \\
(3330)\end{array}$ & $\begin{array}{l}10.39 \\
(1.22)\end{array}$ & $\begin{array}{l}7.08 \\
(0.74) \star\end{array}$ & $\begin{array}{l}6.26 \\
(0.48) \star\end{array}$ & $\begin{array}{l}4.39 \\
(0.39) \star\end{array}$ & $\begin{array}{l}5.81 \\
(0.39)\end{array}$ \\
\hline & & & & & & & $\star \star$ & & & & $\star \star$ \\
\hline & TNG & $\begin{array}{l}535 \\
(434)\end{array}$ & $\begin{array}{l}611 \\
(740)\end{array}$ & $\begin{array}{l}27.44 \\
(56.11) \\
\star\end{array}$ & $\begin{array}{l}338 \\
(610)\end{array}$ & $\begin{array}{l}435 \\
(2011)\end{array}$ & $\begin{array}{l}7.33 \\
(0.76)\end{array}$ & $\begin{array}{l}3.92 \\
(1.1)^{*}\end{array}$ & $\begin{array}{l}1.93 \\
(1.1)^{*}\end{array}$ & $\begin{array}{l}3.84 \\
(0.52) \star\end{array}$ & $\begin{array}{l}3.52 \\
(0.47) \\
9\end{array}$ \\
\hline \multirow[t]{5}{*}{ HF } & Rest & $\begin{array}{l}675 \\
(52)\end{array}$ & $\begin{array}{l}189 \\
(23)^{*}\end{array}$ & $\begin{array}{l}334 \\
(49)^{\star}\end{array}$ & $\begin{array}{l}604 \\
(389)\end{array}$ & $\begin{array}{l}384 \\
(136)\end{array}$ & $\begin{array}{l}4.17 \\
(0.09)\end{array}$ & $\begin{array}{l}1.96 \\
(0.13)^{\star}\end{array}$ & $\begin{array}{l}1.19 \\
(0.08)^{*}\end{array}$ & $\begin{array}{l}1.03 \\
(0.04)^{\star}\end{array}$ & $\begin{array}{l}1.43 \\
(0.06)\end{array}$ \\
\hline & $\begin{array}{l}\text { Tilt } \\
70\end{array}$ & $\begin{array}{l}118 \\
(80)\end{array}$ & $\begin{array}{l}75 \\
(51)\end{array}$ & 51 & $\begin{array}{l}91 \\
(110)\end{array}$ & $\begin{array}{l}75 \\
(61) 9\end{array}$ & $\begin{array}{l}2.33 \\
(0.29)\end{array}$ & $\begin{array}{l}1.16 \\
(0.7)^{*}\end{array}$ & $\begin{array}{l}1.11 \\
(0.14)^{\star}\end{array}$ & $\begin{array}{l}0.74 \\
(0.7)^{*}\end{array}$ & $\begin{array}{l}0.99 \\
(0.04)\end{array}$ \\
\hline & & $\star \star$ & & & & $\star \star$ & $\star \star$ & & & & $\star \star$ \\
\hline & & & & $(30)$ * & & & & & & & \\
\hline & TNG & $\begin{array}{l}84 \\
(26)\end{array}$ & $\begin{array}{l}155 \\
(218)\end{array}$ & $\begin{array}{l}5.42 \\
(7.03) \\
*\end{array}$ & $\begin{array}{l}203 \\
(467)\end{array}$ & $\begin{array}{l}134 \\
(198)\end{array}$ & $\begin{array}{l}1.29 \\
(0.18)\end{array}$ & $\begin{array}{l}0.97 \\
(0.22) \star\end{array}$ & $\begin{array}{l}0.48 \\
(0.16) *\end{array}$ & $\begin{array}{l}0.69 \\
(0.15) *\end{array}$ & $\begin{array}{l}0.73 \\
(0.13) \\
9\end{array}$ \\
\hline \multirow[t]{4}{*}{ LF/HF } & Rest & $\begin{array}{l}0.68 \\
(0.12)\end{array}$ & $\begin{array}{l}1.58 \\
(0.45) \star\end{array}$ & $\begin{array}{l}0.83 \\
(0.13) \star\end{array}$ & $\begin{array}{l}1.00 \\
(0.32) \star\end{array}$ & $\begin{array}{l}0.99 \\
(0.13)\end{array}$ & $\begin{array}{l}3.42 \\
(0.23)\end{array}$ & $\begin{array}{l}4.14 \\
(0.14) \star\end{array}$ & $\begin{array}{l}5.16 \\
(0.36) *\end{array}$ & $\begin{array}{l}4.57 \\
(0.46) \star\end{array}$ & $\begin{array}{l}4.43 \\
(0.15) \\
9\end{array}$ \\
\hline & $\begin{array}{l}\text { Tilt } \\
70\end{array}$ & $\begin{array}{l}4.29 \\
(1.52)\end{array}$ & $\begin{array}{l}5.10 \\
(2.03)\end{array}$ & $\begin{array}{l}4.30 \\
(3.17)\end{array}$ & $\begin{array}{l}3.76 \\
(3.41)\end{array}$ & $\begin{array}{l}4.34 \\
(1.67)\end{array}$ & $\begin{array}{l}4.48 \\
(0.47)\end{array}$ & $\begin{array}{l}6.09 \\
(0.80) *\end{array}$ & $\begin{array}{l}5.62 \\
(0.95) *\end{array}$ & 5.88 & $\begin{array}{l}5.86 \\
(0.49)\end{array}$ \\
\hline & & $\star \star$ & & & & $\star \star$ & $\star \star$ & & & (0.02) & \\
\hline & & & & & & & & & & & $\star \star$ \\
\hline \multicolumn{12}{|c|}{ *= Significant difference between control and each syncope groups } \\
\hline \multicolumn{12}{|c|}{$\star \star=$ Significant difference resting and tilt 70 values } \\
\hline \multicolumn{12}{|c|}{ I = Significant difference between case and control group } \\
\hline \multicolumn{12}{|c|}{$\begin{array}{l}\mathrm{HRV}=\text { Heart rate variability, SBPV = Systolic blood pressure variability, } \mathrm{Cl}=\text { Cardioinhibitory, } \mathrm{VD}=\text { Vasodepressor, } \\
\text { Mixed }=\text { Mixed type, } \mathrm{LF}=\mathrm{Low} \text { frequency in } \mathrm{HRV} \text { by } \mathrm{ms}^{2} \text { and in SBPV by } \mathrm{mmHg}^{2}, \mathrm{HF}=\text { High frequency in } \mathrm{HRV} \text { by } \mathrm{ms}^{2} \\
\text { and in SBPV by } \mathrm{mmHg} \text {. }\end{array}$} \\
\hline
\end{tabular}




\begin{tabular}{|c|c|c|c|c|c|c|c|c|c|c|}
\hline TNG & $\begin{array}{l}5.42 \\
(2.6)\end{array}$ & $\begin{array}{l}5.13 \\
(2.05)\end{array}$ & $\begin{array}{l}2.99 \\
(3.60)\end{array}$ & $\begin{array}{l}4.44 \\
(2.59)\end{array}$ & $\begin{array}{l}4.48 \\
(2.15)\end{array}$ & $\begin{array}{l}5.80 \\
(0.76)\end{array}$ & $\begin{array}{l}4.08 \\
(0.99) *\end{array}$ & $\begin{array}{l}4.02 \\
(1.58) *\end{array}$ & $\begin{array}{l}5.57 \\
(1.44) \star\end{array}$ & $\begin{array}{l}4.84 \\
(0.65)\end{array}$ \\
\hline \multicolumn{11}{|c|}{ *= Significant difference between control and each syncope groups } \\
\hline \multicolumn{11}{|c|}{$\star \star=$ Significant difference resting and tilt 70 values } \\
\hline \multicolumn{11}{|c|}{ q = Significant difference between case and control group } \\
\hline \multicolumn{11}{|c|}{$\begin{array}{l}\mathrm{HRV}=\text { Heart rate variability, SBPV }=\text { Systolic blood pressure variability, } \mathrm{Cl}=\text { Cardioinhibitory, VD = Vasodepressor, } \\
\text { Mixed = Mixed type, } \mathrm{LF}=\mathrm{Low} \text { frequency in } \mathrm{HRV} \text { by } \mathrm{ms}^{2} \text { and in SBPV by } \mathrm{mmHg}^{2}, \mathrm{HF}=\text { High frequency in } \mathrm{HRV} \text { by } \mathrm{ms}^{2} \\
\text { and in SBPV by } \mathrm{mmg}^{2} \text {. }\end{array}$} \\
\hline
\end{tabular}

Fluctuations of HRV during HUTT (table 2):

Phase 1: Patients in the syncope group showed a significantly lower LF and HF flactuations and higher LF/HF ratio with respect to the controls $(\mathrm{P}<0.001)$.

Phase 2: In comparison with the resting state, LF activity did not change but HF activity decreased and the LF/HF ratio increased significantly in both groups $(P<0.001)$. During tilt, LF activity was not statistically different between groups $(P=0.8)$ but HF activity was significantly lower in cases $(P=0.04)$. The LF/HF ratio was not different between study groups $(p=0.9)$

Phase 3: There was no statistical difference in LF ( $p=0.8), \operatorname{HF}(p=0.3)$, and LF/HF $(p=0.2)$ ratio between groups during phase 3 of HUTT.

\section{Fluctuations of SBPV during HUTT (table 2):}

Phase 1: LH and HF powers of SBPV had lower flactuations and the LF/HF ratio was higher in cases vs. controls ( $p<$ $0.001)$.

Phase 2: The fluctuations of LF, HF, and LF/HF ratio was similar to phase 1.

Phase 3: LH and HF powers of SBPV had lower flactuations and the LF/HF ratio was lower in cases vs. controls $(p<$ $0.001)$.

For a better understanding of results, the entire data were divided into consecutive 30 seconds blocks during each phase of HUTT, the mean values of each block were calculated, and separate graphs for LF, HF, and LF/HF ratio fluctuations in HRV and SBPV in cases and controls were drawn. (Figures 1-3). Figure 1 upper and lower panel shows the fluctuations of LF between case and control groups in HRV and SBPV, respectively. In addition to the findings mentioned above, the dominant result is the slow fluctuations of LF in HRV during phase 2. In phase 3, fluctuations increased in both groups without significant difference. Conversely, in SBPV, there was a continuous decrement in LF power, which was shown in both groups in all phases of HUTT. Figure 2 upper and lower panel shows the fluctuations of HF between case and control groups in HRV and SBPV, respectively. After tilting, the activity of HF decreased significantly in HRV and SBPV. After that, HF activity remained low in both groups; the exception was increased activity during the early minutes of phase 3 in the HRV power of syncope patients. Figure 3 upper and lower panel shows the fluctuations of the LF/ HF ratio between cases and controls in HRV and SBPV, respectively. During phase 1 and 2 of the test, the LF/HF ratio of SBPV, although lower in controls compared to cases, increased in both groups similarly during the test, but just after starting phase 3 , there was a rapid reversal of this ratio in syncope patients mainly driven by oscilations in its LF power.

\section{Discussion}


This study is one of the few studies that evaluated simultaneous beat-to-beat HRV and SBPV in patients with and without syncope during the HUTT. The main result of this study, aside from showing the feasibility of these mesurements dring HUTT, was the clarification of LF fluctuations of SBPV during syncope. As mentioned before, the LF power of the $\mathrm{HRV}$ is under the influence of many factors like venous return, cardiac filling, cardiac filling, the baroreceptor reflexes, and the cardiac sympathetic activity 7,8. However, the LF power in SBPV is the pure reflection of the sympathetic nervous system activity ${ }^{9}$. We showed (figure 1 ) that LF fluctuations in SBPV continuously decreased in all stages of HUTT in both case and control groups but with a steeper decrease in patients with syncope. This finding can help to improve our knowledge about the exact role of sympathetic activity during syncope and the phenomenon of sympathetic withdrawal 22

Phase 1 (Supine): patients included in this study were otherwise healthy people without any comorbidities. Considering the normal values of HRV indices reported by Nunan et al. ${ }^{23}$, the LF and HF powers of our patients in the control group were within the normal limit. Conversely, patients with syncope had lower than normal values that were compatible with the findings of other studies ${ }^{24,25}$. In SBPV analysis, the differences in flacuations of LF and HF in each group of patients were discordant and statistically significant. On the other hand, the fluctuations in LF and HF powers of HRV were concordant and statistically similar (figures 1,2). The reason for this phenomenon needs to be elucidated further but clearly it hints different mechanisms for producing these flactuations in HRV vs. SBPV.

Phase 2 (Passive Tilt): the LF power of SBPV showed continuous decrement during this phase, which was different from the plateau pattern of LF power of HRV. Conflicting results about the LF power activity during the passive phase of HUTT has been reported, showing plateau responses ${ }^{26}$, increased activity ${ }^{27}$, and decreased activity ${ }^{28}$. Therefore the pattern of LF power activity in SBPV may be a correct response because it is not under the influence of other factors like baroreceptor sensitivity. Moke et al. reported the same results in their study on children with syncope ${ }^{29}$. The HF power, which is a marker of parasympathetic activity in HRV and SBPV ${ }^{30,31}$, decreased significantly in this phase in acordance by the findings of other studies ${ }^{32}$. Lowering of parasympathetic activity may act as a protective mechanism against developing syncope. Previous studies have sugested the essential role of increased parasympathetic activity in the genesis of syncope ${ }^{33}$. Nine of our patients developed syncope during this phase while the HF power was very low chalenging the original role of parasympatetic activity in syncope. While the LF/HF ratio increased significantly in both HRV and SBPV, the difference between case and control was not significant statistically in HRV, and curves had an overlap on each other (Figure 3). Efremov et al. reported in their study that the LF/HF ratio is not different between case and control groups ${ }^{27}$. Therefore when the LF flactuations in HRV are not a reliable marker of sympathetic activity, it is better to use LF/HF ratio in SBPV as a marker of sympathovagal balance in which the LF component is a pure reflection of sympathetic activity. In this regard, decrement of the LF/HF ratio in the second part of HUTT in the case group can be a sign of autonomic insufficiency.

Phase 3 (Active Tilt): a small and non-significant increase in LF power of HRV and SBPV was seen, that may be the effects of nitroglycerine, which decreases baroreceptor sensitivity and increases sympathetic activity ${ }^{34}$. Non-significant changes of HF power activity (both HRV and SBPV) is aligned with the findings that sublingual nitroglycerine makes little changes in parasympathetic activity and tends to decrease it ${ }^{34}$. Twenty-two of our patients developed syncope in this phase. Sixteen of theses syncopes were vasodilatory or mixed type, which share the component of vasodilatation.

Sublingual nitroglycerine provokes syncope by decreasing the stroke volume and inducing vasodilatation ${ }^{35}$. Therefore these subtle changes in HRV and SBPV indices most probably are not related to the effects of nitroglycerine on the ANS but on the other hand might be linked to the failure of the ANS to tolerate to the aditional hemodynamic burden imposed by nitroglycerine in patients with syncope. 


\section{Conclusion}

Our findings show an abnormal autonomic function in patients with syncope, both at rest and tilting. Fluctuations of spectral indices of beat-to-beat SBPV, a potential noval index of pure sympathetic activity, show an exaggerated response during tilt and its withdrawal before syncope. Real-time spectral analysis of HRV and SBPV is feasible during HUTT, and the results of each method may open new insights into the mechanisms behind NMS.

\section{Limitations}

This study may suffer from some limitations:

1- Patients in the control group were not normal people without a history of syncope. The respective positivity rate with HUTT in subjects without syncope ranges from 11 to $14 \%{ }^{36}$. Patients in the control group had normal ranged HRV indices, and there were continuous and significant differences between HRV indices between the case and control groups at rest. Therefor we assume that the effects of our control in the results of the study were negligible.

2- The sample volume was too small to analyse the results in patients with different types of syncope.

3- The time of performing HUTT in our study was in the afternoon. There is a diurnal variation in the occurrence of syncope, more prevalent during the morning ${ }^{37}$. Therefore we may face some limitations in this regard.

4- Because of the low sample volume, we didn't analyse the results based on gender.

\section{Declarations}

Ethics approval and consent to participate: Ethics approval and consent to participate in this study was approved by Research Ethics Committee of Tabriz University of Medical Sciences, Tabriz, Iran (registration number:

IR.TBZMED.REC.1397.602). This study was conducted in accordance with the revised Helsinki Declaration regarding ethical principles for medical research involving human subjects. All relevant approvals were obtained prior to initiation of this study. All participants signed a written consent form.

Consent for publication: A written informed consent for the publication of their details under the Creative Commons Attribution License 4.0 were obtained from all participants.

Availability of data and materials: The datasets used and analysed during the current study are available from the corresponding author on reasonable request.

Competing interests: The authors declare that they have no competing interests.

Funding: no funding was available.

Authors' contributions: All authors contributed equally to the design and conduction of the study. AK and FA conducted the tilt tests and collected the data, FA analyzed and interpreted the patient data, and BK was a major contributor in writing the manuscript. All authors read and approved the final manuscript.

Acknowledgements: We want to give the best of our thanks to the patients who participated in this study and to Tabriz University of Medical Sciences for approving it. Also, we appreciate our electrophysiology nurse, Maryam Seidgar, for her help in this study.

\section{References}


1. Patel PR, Quinn JV. Syncope: a review of emergency department management and disposition. Clinical and experimental emergency medicine 2015;2:67.

2. Carol Chen-Scarabelli TMS. Neurocardiogenic syncope. BMJ 2004 2004;329:336-341.

3. Jeffrey P. Moak M, FACC, James J. Bailey, MD, MSC, Fairouz T. Makhlouf, BS. Simultaneous Heart Rate and Blood Pressure Variability Analysis: Insight Into Mechanisms Underlying Neurally Mediated Cardiac Syncope in Children. JACC 20021466-1474.

4. Torabi P, Ricci F, Hamrefors V, Melander O, Sutton R, Benditt DG, Fedorowski A. Impact of Cardiovascular Neurohormones on Onset of Vasovagal Syncope Induced by Head-up Tilt. Journal of the American Heart Association 2019;8:e012559.

5. Pagani M, Lombardi F, Guzzetti S, Rimoldi O, Furlan R, Pizzinelli P, Sandrone G, Malfatto G, Dell'Orto S, Piccaluga E. Power spectral analysis of heart rate and arterial pressure variabilities as a marker of sympatho-vagal interaction in man and conscious dog. Circulation research 1986;59:178-193.

6. Ori Z, Monir G, Weiss J, Sayhouni X, Singer DH. Heart rate variability. Frequency domain analysis. Cardiology clinics Aug 1992;10:499-537.

7. J. FORTIN WH, R. GRUELLENBERGER, P. WACH, F. SKRABAL. Real-Time monitor for hemodynamic beat-to-beat parameters and power spectra analysis of the biosignals. Paper presented at: Engineering in Medicine and Biology Society,1998; Hong Kong.

8. Parati G, Omboni S, Frattola A, Di Rienzo M, Zanchetti A, Mancia G. Dynamic evaluation of the baroreflex in ambulant subjects. Blood pressure and heart rate variability 1992123-137.

9. Ponchon P, Elghozi J. Contribution of humoral systems to the short-term variability of blood pressure after severe hemorrhage. American Journal of Physiology-Regulatory, Integrative and Comparative Physiology 1997;273:R58R69.

10. Kouakam C, Lacroix D, Zghal N, Logier R, Klug D, Le Franc P, Jarwe M, Kacet S. Inadequate sympathovagal balance in response to orthostatism in patients with unexplained syncope and a positive head up tilt test. Heart 1999;82:312-318.

11. Lipsitz LA, Mietus J, Moody GB, Goldberger AL. Spectral characteristics of heart rate variability before and during postural tilt. Relations to aging and risk of syncope. Circulation 1990;81:1803-1810.

12. Furlan R, Piazza S, Dell'Orto S, Barbic F, Bianchi A, Mainardi L, Cerutti S, Pagani M, Malliani A. Cardiac autonomic patterns preceding occasional vasovagal reactions in healthy humans. Circulation 1998;98:1756-1761.

13. Morillo CA, Klein GJ, Jones DL, Yee R. Time and frequency domain analyses of heart rate variability during orthostatic stress in patients with neurally mediated syncope. The American journal of cardiology 1994;74:12581262.

14. Lipsitz LA, Hayano J, Sakata S, Okada A, Morin RJ. Complex demodulation of cardiorespiratory dynamics preceding vasovagal syncope. Circulation 1998;98:977-983.

15. Rivera AL, Estanol B, Senties-Madrid H, Fossion R, Toledo-Roy JC, Mendoza-Temis J, Morales IO, Landa E, RoblesCabrera A, Moreno R. Heart rate and systolic blood pressure variability in the time domain in patients with recent and long-standing diabetes mellitus. PloS one 2016;11.

16. Makowiec D, Graff B, Struzik ZR. Multistructure index characterization of heart rate and systolic blood pressure reveals precursory signs of syncope. Scientific Reports 2017/03/24 2017;7:419.

17. Piccirillo G, Naso C, Moisè A, Lionetti M, Nocco M, Di Carlo S, De Laurentis T, Magrì D, Cacciafesta M, Marigliano V. Heart rate and blood pressure variability in subjects with vasovagal syncope. Clinical science (London, England: 1979) Jul 2004;107:55-61. 
18. Makowiec D, Graff B, Struzik ZR. Multistructure index characterization of heart rate and systolic blood pressure reveals precursory signs of syncope. Sci Rep Mar 24 2017;7:419.

19. Bartoletti A, Alboni P, Ammirati F, Brignole M, Del Rosso A, Foglia Manzillo G, Menozzi C, Raviele A, Sutton R. 'The Italian Protocol': a simplified head-up tilt testing potentiated with oral nitroglycerin to assess patients with unexplained syncope. Europace: European pacing, arrhythmias, and cardiac electrophysiology : journal of the working groups on cardiac pacing, arrhythmias, and cardiac cellular electrophysiology of the European Society of Cardiology Oct 2000;2:339-342.

20. Fortin J, Fellner C, Mocnik N, Grond J, Brunner T, Flotzinger D. The importance of VERIFI ("Vasomotoric Elimination and Reconstructed Identification of the Initial set-point”) for the performance of the CNAP technology. EMBEC \& NBC 2017: Springer; 2017:663-666.

21. Schroeder C, Tank J, Heusser K, Diedrich A, Luft FC, Jordan J. Physiological phenomenology of neurally-mediated syncope with management implications. PloS one 2011;6.

22. Kamiya A, Hayano J, Kawada T, Michikami D, Yamamoto K, Ariumi H, Shimizu S, Uemura K, Miyamoto T, Aiba T. Low-frequency oscillation of sympathetic nerve activity decreases during development of tilt-induced syncope preceding sympathetic withdrawal and bradycardia. American Journal of Physiology-Heart and Circulatory Physiology 2005;289:H1758-H1769.

23. David NUNAN PDGRHS, PH.D. and DAVID A. BRODIE, PH.D. A Quantitative Systematic Review of Normal Values for Short-Term Heart Rate Variability in Healthy Adults. PACE 2010;33:1407-1417.

24. Trivedi G, Saboo B, Singh R, Maheshwari A, Sharma K, Verma N. Can decreased heart rate variability be a marker of autonomic dysfunction, metabolic syndrome and diabetes? Journal of Diabetology May 1, 2019 2019;10:48-56.

25. Shim SH, Park S-Y, Moon SN, Oh JH, Lee JY, Kim HH, Han JW, Lee SJ. Baseline heart rate variability in children and adolescents with vasovagal syncope. Korean journal of pediatrics 2014;57:193.

26. Miranda CM, Silva RMFLd. Analysis of heart rate variability before and during tilt test in patients with cardioinhibitory vasovagal syncope. Arquivos brasileiros de cardiologia 2016;107:568-575.

27. Efremov K, Brisinda D, Venuti A, lantorno E, Cataldi C, Fioravanti F, Fenici R. Heart rate variability analysis during head-up tilt test predicts nitroglycerine-induced syncope. Open Heart 2014;1.

28. Sato Y, Ichihashi K, Kikuchi Y, Shiraishi H, Momoi MY. Autonomic function in adolescents with orthostatic dysregulation measured by heart rate variability. Hypertension Research 2007;30:601-605.

29. Moak JP, Bailey JJ, Makhlouf FT. Simultaneous heart rate and blood pressure variability analysis: Insight into mechanisms underlying neurally mediated cardiac syncope in children. Journal of the American College of Cardiology 2002;40:1466-1474.

30. Shaffer F, Ginsberg J. An overview of heart rate variability metrics and norms. Frontiers in public health 2017;5:258.

31. Goh CH, Ng SC, Kamaruzzaman SB, Chin AV, Tan MP. Standing beat-to-beat blood pressure variability is reduced among fallers in the Malaysian Elders Longitudinal Study. Medicine (Baltimore) Oct 2017;96:e8193.

32. Marquez MF, Gómez-Flores JR, González-Hermosillo JA, Ruíz-Siller TdJ, Cardenas M. Role of the sympathetic nervous system in vasovagal syncope and rationale for beta-blockers and norepinephrine transporter inhibitors. Medwave 2016;16.

33. Adkisson WO, Benditt DG. Syncope due to Autonomic Dysfunction: Diagnosis and Management. The Medical Clinics of North America 2015;99:691-710.

34. Gori T, Floras JS, Parker JD. Effects of nitroglycerin treatment on baroreflex sensitivity andshort-term heart rate variability in humans. Journal of the American College of Cardiology 2002;40:2000-2005.

35. Gisolf J, Westerhof BE, van Dijk N, Wesseling KH, Wieling W, Karemaker JM. Sublingual nitroglycerin used in routine tilt testing provokes a cardiac output-mediated vasovagal response. Journal of the American College of Cardiology

Page $11 / 16$ 
2004;44:588-593.

36. Brignole M, Moya A, de Lange FJ, Deharo J-C, Elliott PM, Fanciulli A, Fedorowski A, Furlan R, Kenny RA, Martín A. 2018 ESC Guidelines for the diagnosis and management of syncope. European heart journal 2018;39:1883-1948.

37. Lewis NC, Atkinson G, Lucas SJ, Grant EJ, Jones H, Tzeng YC, Horsman H, Ainslie PN. Diurnal variation in time to presyncope and associated circulatory changes during a controlled orthostatic challenge. American journal of physiology Regulatory, integrative and comparative physiology Jul 2010;299:R55-61.

\section{Figures}

A

LF , HRV, between patients with and without syncope during HUTT

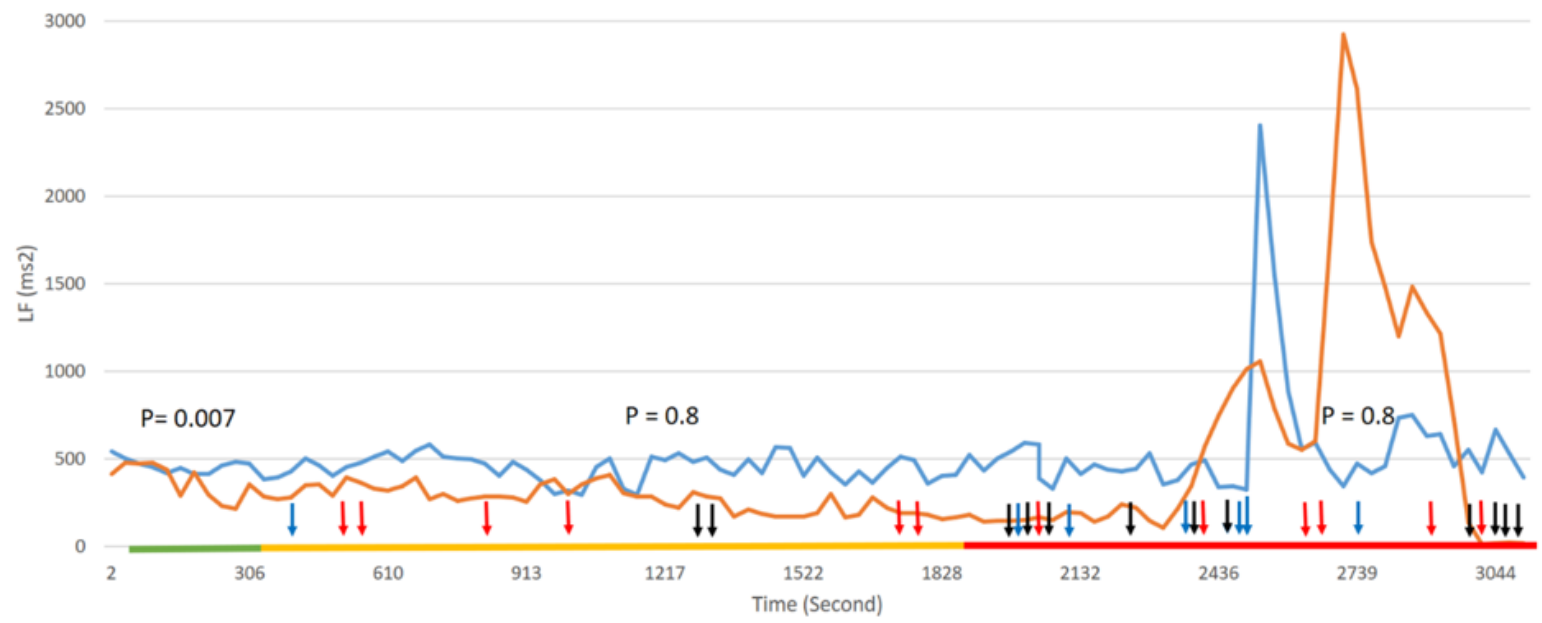

Green $=$ Rest, Yellow $=$ Tilt 70, Red $=$ TNG - No Syncope - Syncope Arrows: Red $=$ Cardioinhibitory, Blue= Vasodepressor, Black $=$ Mixed type

B. $\quad L F, S B P V$, in patients with and without syncope during HUTT

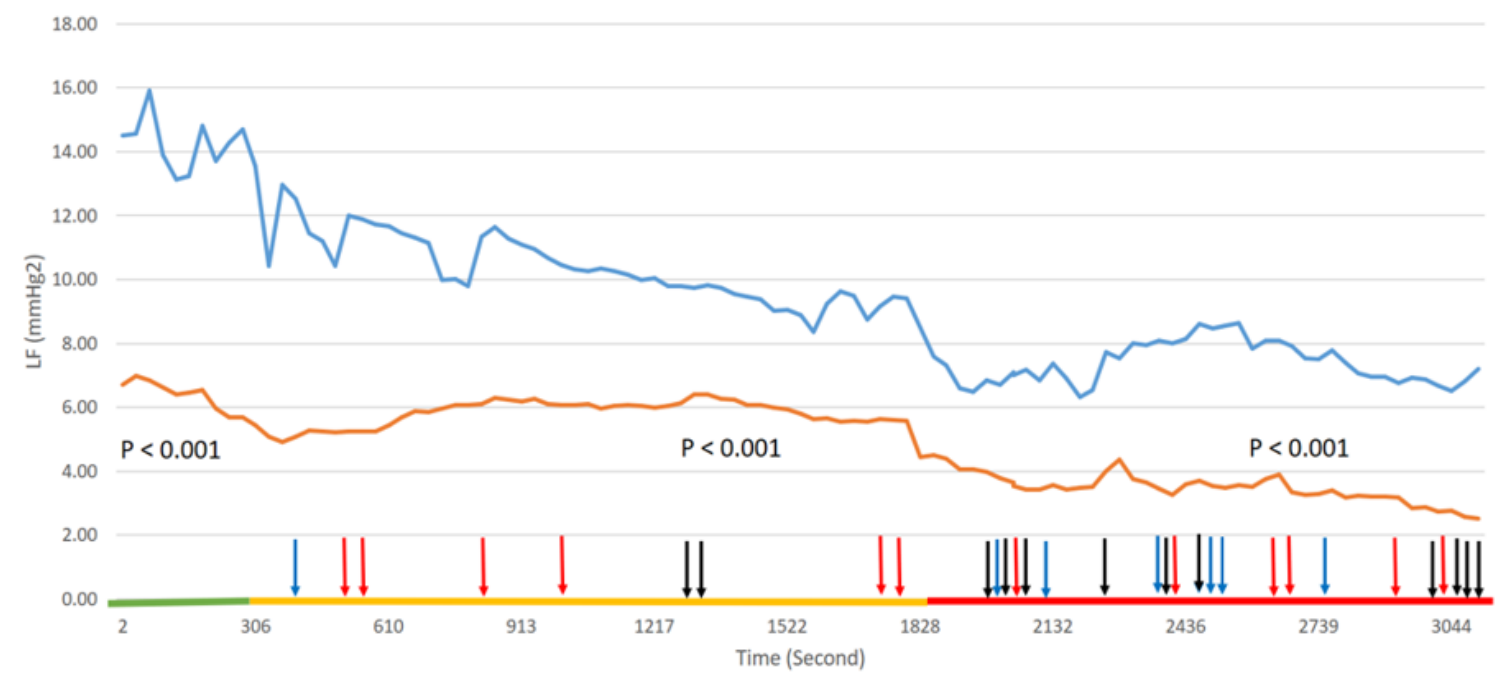

Green $=$ Rest, Yellow $=$ Tilt 70, Red $=$ TNG - Wo Syncope - Syncope $\quad$ Arrows: Red $=$ Cardioinhibitory, Blue $=$ Vasodepressor, Black $=$ Mixed type

\section{Figure 1}


Comparison of LF in HRV and SBPV in patients with and without syncope during HUTT. Arrows: Time of syncope, LF= Low frequency, HRV= Heart rate variability, SBPV= Systolic blood pressure variability, HUTT= Head up tilt test. A. The upper panel shows the LF (ms2) activity among case and control groups in the field of HRV, which shows the low activity of LF at the beginning of the HUTT in the case group $(P<0.001)$. After that, while the activity remains unchanged in the control group, in the case group, the activity became smaller gradually during the entire phases of 1,2 , and up to midtime phase 3 (the difference between groups was not significant). In the second half of phase 3 , in 11 patients who developed syncope, the activity of LH increased significantly, even more than the control group. During the last seconds of HUTT, the LH activity in the case group fell to a very low and undetectable level. B. The lower panel shows the LF (mmHg2), SBPV, activity among case and control groups. LF was lower significantly in the case than the control group. With advancing the HUTT, the activity of LF decreased in both groups. This decrement was smaller in the case group during phase 2 of the study. The differences between study groups were significant in all phases of the study $(P<0.001)$.

A

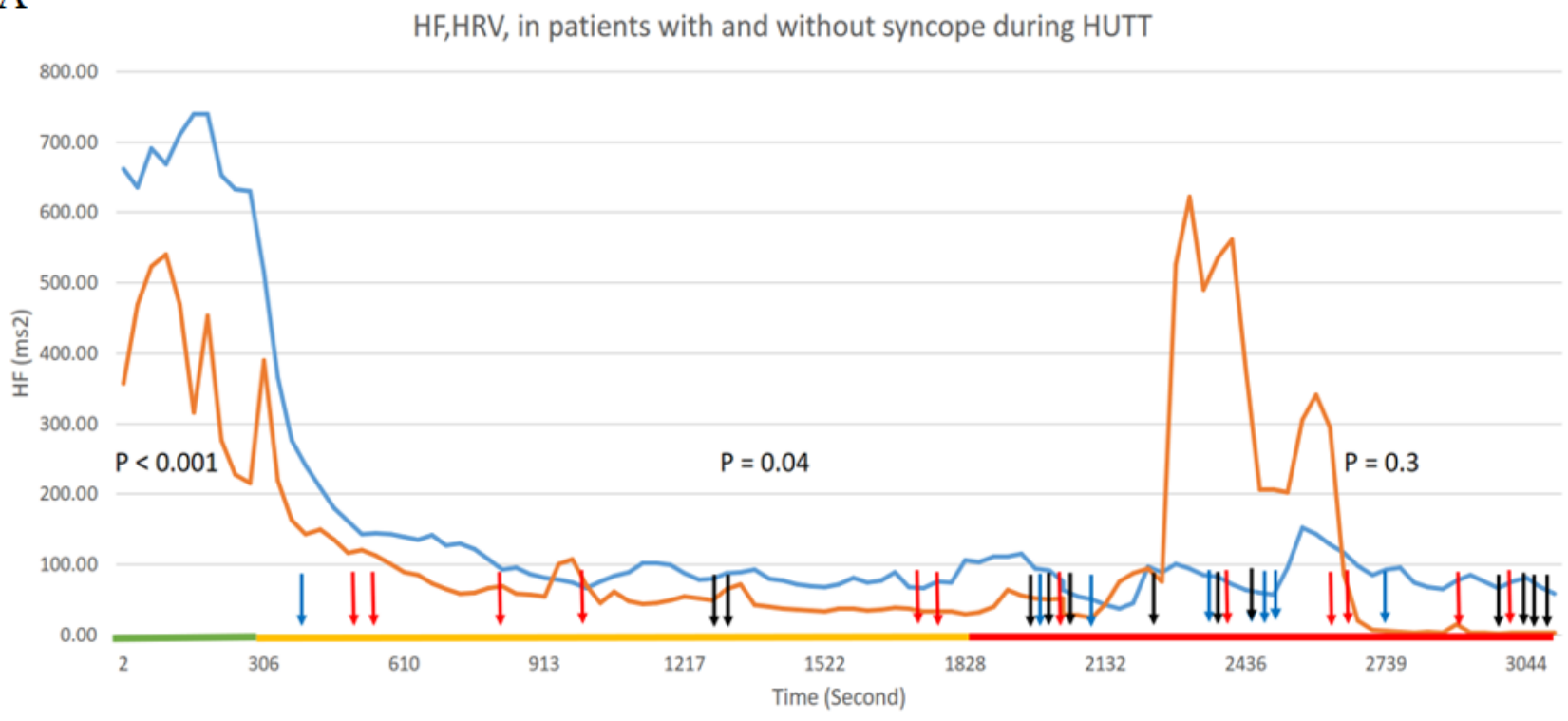

Green $=$ Rest, Yellow $=$ Tilt 70, Red $=$ TNG - No Syncope $\quad$ - Syncope $\quad$ Arrows: Red $=$ Cardioinhibitory, Blue= Vasodepressor, Black $=$ Mixed type

B

HF, SBPV, in patients with and without syncope during HUTT

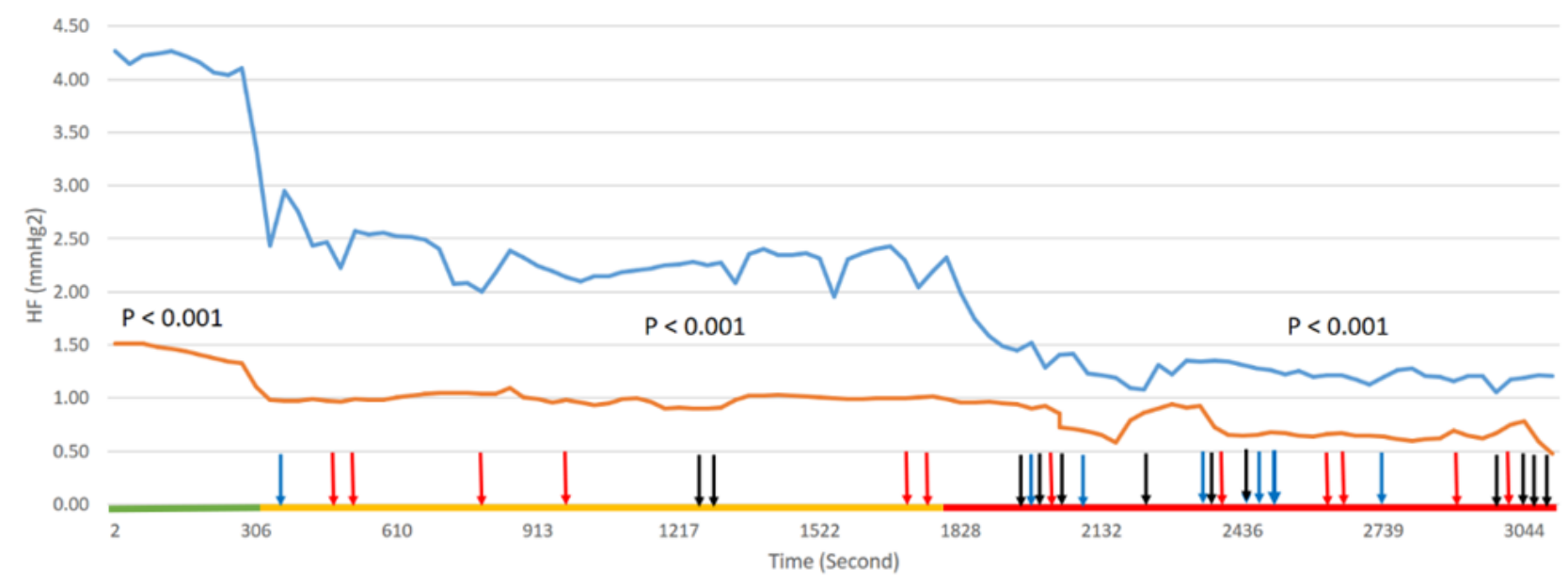

Green $=$ Rest, Yellow $=$ Tilt 70, Red = TNG - No Syncope - Syncope - Column1 Arrows: Red = Cardioinhibitory, Blue= Vasodepressor, Black = Mixed type

Figure 2

Page $13 / 16$ 
Comparison of HF in HRV and SBPV in patients with and without syncope during HUTT. Arrows: Time of syncope, HF= High frequency, HRV= Heart rate variability, SBPV= Systolic blood pressure variability, HUTT= Head up tilt test. A. The upper panel compares HF (ms2) of HRV. During the initial resting phase of the study, the HF was lower in the case than the control group. Soon after starting phase 2 of HUTT (passive tilt $70^{\circ}$ ), HF activity decreased dramatically in both case and control groups. The level of activity was low in both groups during phase 2 of the study. After provocation with TNG, in the case group, the HF activity jumped to a very high level transiently, but after about 10 minutes fell to an undetectable level. The differences in HF activity were significant in phase 1 and 2 between the case and control group $P$ $<0.001$. B. The lower panel shows HF ( $\mathrm{mmHg} 2)$ in SBPV among case and control groups. Like HF in HRV, HF activity in SBPV was lower in the case than the control group, $P<0.001$. Starting phase 2 of the study was accompanied by the rapid falling of the activity of HF in both groups, which was more prominent in the control group. The activity of HF in both groups showed a plateau during phase 2 of HUTT. Again the difference between the two groups was significant $\mathrm{P}<$ 0.001. HF decreased rapidly with the starting of phase 3 of HUTT. This decrement was higher in the control group. During the rest of this phase, the case and control groups showed a plateau activity of HF. The difference was significant between groups, $\mathrm{P}<0.001$. 


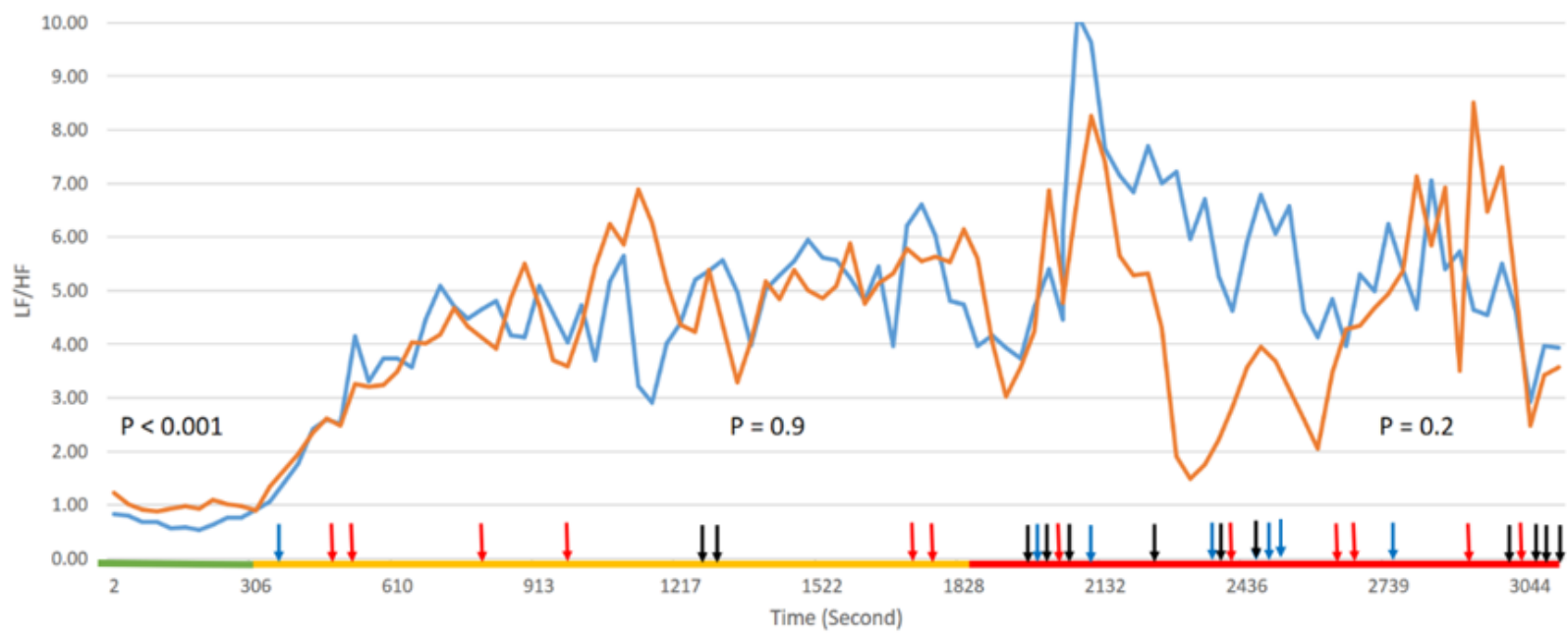

Green $=$ Rest, Yellow $=$ Tilt 70, Red $=$ TNG — No Syncope LF $/$ HF $\quad$ - Syncope LF $/$ HF Arrows: Red $=$ Cardioinhibitory, Blue $=$ Vasodepressor, Black $=$ Mixed type

B

LF/HF ratio, SBPV, in patients with and without syncope during HUTT

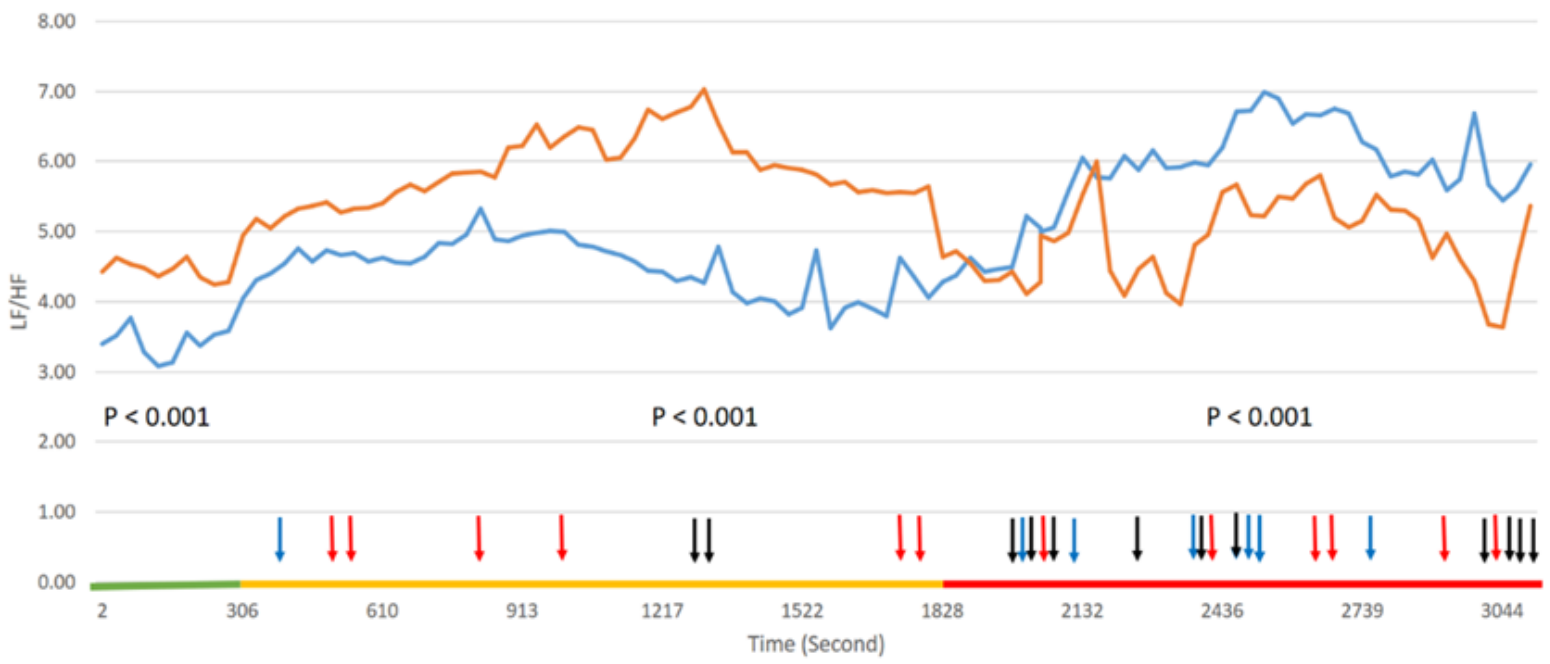

Green $=$ Rest, Yellow $=$ Tilt 70, Red $=$ TNG

—No Syncope —-Syncope Arrows: Red = Cardioinhibitory, Blue= Vasodepressor, Black = Mixed type

\section{Figure 3}

Comparison of LF/HF ratio in HRV and SBPV in patients with and without syncope during HUTT. Arrows: Time of syncope, LF= Low frequency, HF= High frequency, HRV= Heart rate variability, SBPV= Systolic blood pressure variability, HUTT = Head up tilt test. A. The upper panel of this figure shows the LF/HF ratio of HRV in case and control groups. Unlike the LF and HF, in the resting phase of HUTT, LF/HF ratio was lower in the control group, $P<0.001$. With the beginning of phase 2 , the LF/HF ratio increased gradually and reached its plateau after about 8 minutes. The difference between the case and control groups was not significant. Phase 3 was accompanied by fluctuations in the LF/HF ratio in both groups that were not significant. B. The lower panel shows the LF/HF ratio in the field of SBPV. The LF/HF ratio was significantly lower in the control group than the case group in the first phase of the study $(P<0.001)$. The first half of Phase 2 of HUTT displays a slight increase in the LF/LH ratio in both study groups. The increment was higher in the case group. During the second half of this phase, the LF/HF ratio decreased gradually in both groups. The difference was significant in this phase $(\mathrm{P}<0.001)$. The beginning of phase 3 was accompanied by further lowering of the LF/HF ratio 
in the case group, while the ratio increased in the control group. In the first half of this phase, the direction on the LF/HF ratio was discordant in study groups. The second half of this phase showed plateau activity of the LF/HF ratio in both groups. The difference was significant between study groups $(P<0.001)$. 